\title{
Curcumin Attenuates Hepatotoxicity Induced by Zinc Oxide Nanoparticles in Rats
}

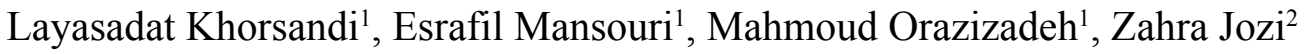 \\ ${ }^{1}$ Cell \& Molecular Research Center, Ahvaz Jundishapur University of Medical Sciences School of Medicine, Ahvaz, Iran \\ ${ }^{2}$ Department of Anatomical Sciences, Ahvaz Jundishapur University of Medical Sciences School of Medicine, Ahvaz, Iran
}

Background: Zinc oxide nanoparticles $(\mathrm{NZnO})$ are increasingly used in modern life. Most metal nanoparticles have adverse effects on the liver.

Aims: To explore the protective action of curcumin (Cur) against hepatotoxicity induced by $\mathrm{NZnO}$ in rats.

Study Design: Animal experimentation.

Methods: Control group animals received normal saline, while the Cur group animals were treated with 200 $\mathrm{mg} / \mathrm{kg}$ of Cur orally for 21 days. NZnO-intoxicated rats received $50 \mathrm{mg} / \mathrm{kg}$ of $\mathrm{NZnO}$ for 14 days by gavage method. In the $\mathrm{NZnO}+\mathrm{Cur}$ group, rats were pretreated with Cur for 7 days before NZnO administration. Plasma activities of Alanine aminotransferase (ALT), aspartate aminotransferase (AST) and alkaline phosphatase (ALP) were measured as biomarkers of hepatotoxicity. Hepatic levels of malondialdehyde (MDA) and superoxide dismutase (SOD) and glutathione peroxidase (GPx) activities were measured for detection of oxidative stress in liver tissue. Histological changes and apoptosis in liver tissue were studied by using Hematoxylin-eosin staining and the transferase dUTP nick end labeling (TUNEL) method.
Results: NZnO induced a significant increase in plasma AST (2.8-fold), ALT (2.7-fold) and ALP (1.97-fold) activity in comparison to the control group $(p<0.01)$. $\mathrm{NZnO}$ increased MDA content and reduced SOD and GPx activities. NZnO caused liver damage including centrilobular necrosis and microvesicular steatosis. The percentage of apoptosis in hepatocytes was increased in NZnO-treated rats $(\mathrm{p}<0.01)$. Pre-treatment of Cur significantly reduced lipid peroxidation (39\%), increased SOD (156\%) and GPx (26\%) activities, and attenuated ALT (47\%), AST (41\%) and ALP (30\%) activities. Pre-treatment with Cur also decreased the histology changes and apoptotic index of hepatocytes $(\mathrm{p}<0.05)$.

Conclusion: These findings indicate that Cur effectively protects against $\mathrm{NZnO}$-induced hepatotoxicity in rats. However, future studies are required to propose Cur as a potential protective agent against hepatotoxicity induced by metal nanoparticles.

Keywords: Antioxidants, curcumin, nanomaterials, oxidative stress
Previous studies showed that nanoparticles (NPs), after administration to laboratory animals, accumulated in the liver, kidney, spleen, brain, lung, etc. $(1,2)$. Sunscreen is the most common way in which NPs are applied. The main component of sunscreens is zinc oxide nanoparticles ( $\mathrm{NZnO})$, which absorbs ultraviolet light (2). NZnO are also used in electronic materials, biosensors, rubber manufacturing, food additives, and pigments (3). In addition, $\mathrm{NZnO}$ is used for its antibacterial and antifungal properties in the food packaging industry (4).
The widespread application of $\mathrm{NZnO}$ might increase the possibility of human exposure through skin contact, ingestion and inhalation.

Although most of the exposure to $\mathrm{NZnO}$ is via skin contact, NZnO do not permeate the epidermis (5). However, small fractions of lip products and sun protection products may be accidentally ingested. $\mathrm{NZnO}$ can be easily ingested when used in water, food packaging or for drug delivery $(6,7)$. The kidneys, liver and spleen are the main target organs for NPs after

Address for Correspondence: Dr. Layasadat Khorsandi, Cell \& Molecular Research Center, Ahvaz Jundishapur University of Medical Sciences School of Medicine, Ahvaz, Iran Phone: +98-611-3336380 e-mail: layasadat@yahoo.com

Received: 5 January 2015 Accepted: 4 November2015 • DOI: 10.5152/balkanmedj.2016.150017

Available at www.balkanmedicaljournal.org 
absorption through the gastrointestinal tract (8). Ben-Slama et al. (9) administered $\mathrm{NZnO}$ through oral gavage to Wistar rats and observed that $\mathrm{NZnO}$ mainly accumulated in liver tissue. In vivo and in vitro studies have demonstrated that $\mathrm{NZnO}$ damages liver cell function and induces apoptosis and oxidative stress in human hepatocytes $(10,11)$.

Medicinal plants are traditionally utilized to treat human disorders. Curcuma longa is one of the most commonly used herbal medicines. Curcumin (Cur) is the main component of the Curcuma longa (12). Many studies reveal the protective or therapeutic effects of Cur in different forms of liver injury such as hepatitis, alcoholic and nonalcoholic fatty change, hepatocellular carcinoma and hepatotoxicity induced by drugs (13-15). Cur has many benefits such as antioxidant, anticancer, anti-inflammatory, anti-hyperlipidemic and antimicrobial effects (12). This study investigated the efficacy of Cur on NZnO- induced hepatotoxicity.

\section{MATERIALS AND METHODS}

\begin{abstract}
Animals
Thirty-two healthy and adult male Wistar rats $(200 \pm 20 \mathrm{~g})$ were used in this experimental study. The rats were housed and maintained in a $12 \mathrm{~h}$ dark-light cycle, with a relative humidity of $50 \pm 5 \%$ and at a temperature of $22 \pm 3^{\circ} \mathrm{C}$. The animals had ad libitum access to commercial food (pellet) and water throughout the experiment. The acclimatization time was at least 1 week. We performed this study according to the guidelines of the institution's Animal Ethics Committee (approve number: CMRC-108).
\end{abstract}

\section{Experimental design}

The animals were divided randomly into four groups. The Control group received saline for 21 consecutive days. In the Cur group, $200 \mathrm{mg} / \mathrm{kg}$ of Cur dissolved in corn oil (16) was given for 21 consecutive days by oral gavage. In the $\mathrm{NZnO}$ group, oral treatment with $\mathrm{NZnO}$ (with a mean size between 20 and $30 \mathrm{~nm}$ ) at the dose of $50 \mathrm{mg} / \mathrm{kg}$ was started on day 7 after the daily administration of $0.2 \mathrm{~mL}$ saline. In the Cur $+\mathrm{NZnO}$ group, Oral treatment with $\mathrm{NZnO}$ at the dose of $50 \mathrm{mg} / \mathrm{kg}$ was started on day 7 after the daily administration of Cur and was continued until the study was terminated on day 21 .

The dose of $\mathrm{NZnO}$ was selected based on our pilot study. In the pilot study, $50 \mathrm{mg} / \mathrm{kg}$ of bulk $\mathrm{ZnO}$ was administered to the 4 rats. Liver histology and ALT, AST and ALP activities were normal in these animals (results not shown). After blood samples were collected on day 22 , the animals were euthanized under slight anesthesia with ether and then their livers were dissected and weighed. Small pieces of the samples were kept in a $-80^{\circ} \mathrm{C}$ freezer for the assessment of lipid peroxidation (MDA), superoxide dismutase (SOD) and glutathione peroxidase (GPx). Other pieces of liver were fixed in $10 \%$ formalin for histological studies and transferase dUTP nick end labeling (TUNEL) staining.

\section{Nanoparticle preparation}

One gr of $\mathrm{ZnO}$ nanopowder (Sigma) was added to $100 \mathrm{~cm}^{3}$ BSA (bovine serum albumin) solution. BSA solution at a concentration of $40 \mathrm{mg} / \mathrm{mL}$ was prepared by dissolving the powder in Milli-Q water at $\mathrm{pH} 4.7$ (isoelectric point of BSA). The mixture was then ultrasonicated for $1 \mathrm{~h}$ (17). A stock solution of $1 \mathrm{mg} / \mathrm{mL} \mathrm{NZnO}$ was prepared in the BSA solution. The mixture was dispersed for $10 \mathrm{~min}$ by using an ultrasonicator and kept at $4^{\circ} \mathrm{C}$. The stock solution was stable for at least 7 days at $4^{\circ} \mathrm{C}$. Just before each administration, the stored solution was diluted and sonicated for 15 minutes. Atomic force microscopy (AFM) was used to characterize the prepared $\mathrm{NZnO}$.

\section{Evolution of serum markers of hepatotoxicity}

The blood samples were obtained from heart cavities and centrifuged. Serum alanine aminotransferase (ALT), aspartate aminotransferase (AST) and alkaline phosphatase (ALP) activities were measured by using commercial kits (Sigma Chemical Company, St. Louis).

\section{Lipid peroxidation assay}

Frozen liver samples were homogenized in a fastprep homogenizer (BIO 101, Inc., Vista; CA, USA) for the assessment of Malondialdehyde (MDA) levels. The lipid peroxidation is determined by the reaction of thiobarbituric acid with MDA and measured according to previous studies (18). Briefly, $0.5 \mathrm{~mL}$ of homogenized samples and $1.5 \mathrm{~mL}$ trichloroacetic acid (10\%) were combined and centrifuged. Then, $1.5 \mathrm{~mL}$ of the supernatant and $2 \mathrm{~mL}$ thiobarbituric acid were mixed and heated to $100^{\circ} \mathrm{C}$ for 0.5 hours. Two $\mathrm{mL}$-butanol was added to the combination and centrifuged. The absorbance of the mixture was read at $532 \mathrm{~nm}$ (VERSAmax spectrophotometer, Molecular Device, USA). Results were reported as nmol MDA eq/g tissue.

\section{SOD activity assay}

SOD (Randox Labs; Crumlin, UK) activity was measured according to previous studies (18). Briefly, Iodonitrotetrazolium chloride reacts with superoxide radical and produces red formazan. Its absorbance was read at $505 \mathrm{~nm}$ (VERSAmax spectrophotometer, Molecular Device, USA), and the results were reported as $\mathrm{U} / \mathrm{mg}$ protein. 


\section{GPx activity assay}

GPx (Randox Labs.; Crumlin, UK) activity was measured according to previous studies (18). In this method, GPx oxidizes reduced glutathione (GSH) to GSSG. The kinetic of NADPH oxidation (consumption) is proportional to GPx activity, and was read at $340 \mathrm{~nm}$ (VERSAmax spectrophotometer, Molecular Device, USA). The results were reported as U/ mg protein (18).

\section{Histology analyses}

Six hematoxylin and eosin (H\&E) stained slides for each animal were considered for the evaluation of histological changes such as the congestion of erythrocytes, inflammatory-cell infiltration and microvesicular steatosis in hepatocytes (fatty change) by using light microscopy.

\section{TUNEL assay}

The paraffin-embedded sections were used for the assessment of apoptosis by using a TUNEL kit (in situ Cell Death Detection, POD kit, Roche; Germany). The slides were incubated with proteinase $\mathrm{K}$ and $5 \%$ of BSA for 0.5 hour in a $37^{\circ} \mathrm{C}$ incubator. After washing, the slides were permeabilized and incubated with TUNEL reaction buffer for 1 hour in the $37^{\circ} \mathrm{C}$ incubator. After washing in PBS (phosphate buffer saline), the slides were incubated in anti-fluorescein-antibody-peroxidase for 0.5 hours at $37^{\circ} \mathrm{C}$. After washing, the slides were incubated with DAB substrate (Roche; Germany). When the slides had developed color, they were quickly immersed in deionized water. Three slides per animal were evaluated in this experiment. Intense, dark brown and homogeneous staining of nuclei indicated TUNEL-positive cells. The percentage of apoptotic cells (apoptotic index) was calculated as previously described (18).

\section{Statistical analysis}

SPSS software version 17 (SPSS Inc; Chicago, IL, USA) was used for statistical analysis. Differences between groups were analyzed by one-way ANOVA and Tukey test. The data were shown as the mean \pm standard deviation. P values less than 0.05 were considered statistically significant.

\section{RESULTS}

\section{Nanoparticle characterization}

The size and morphology of the $\mathrm{NZnO}$ were revealed by AFM. The NPs showed spherical morphology with a mean size between 20 and $30 \mathrm{~nm}$ (Figure 1).
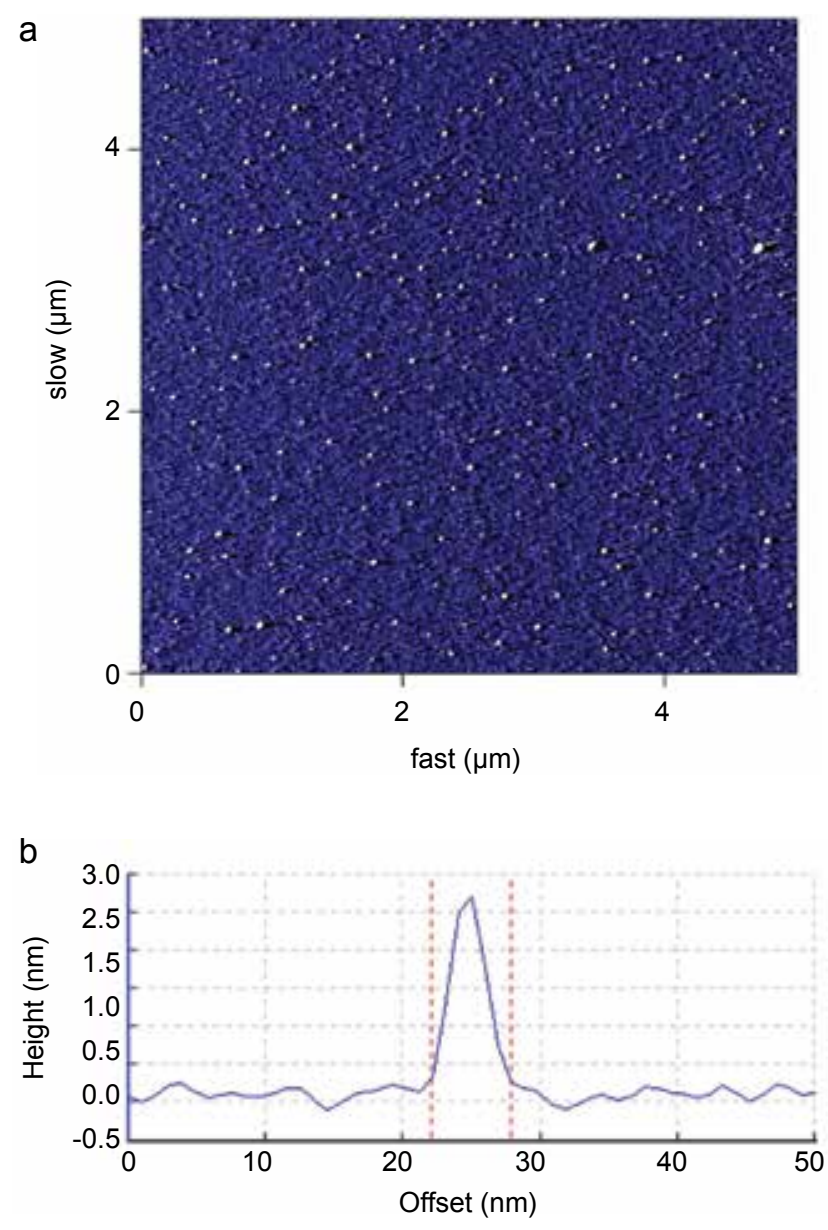

FIG. 1. a, b. AFM image of nanoparticles showed distinct spherical particles (a) in size range between 20 and $30 \mathrm{~nm}$ (b).

\section{Serum markers of hepatotoxicity}

Serum activity of ALT, AST and ALP were slightly reduced in Cur-treated rats in comparison to the control group ( $>0.05$ ). In NZnO-intoxicated rats, serum activity of ALT, AST and ALP were increased 2.7-, 2.8- and 1.97-fold, respectively $(\mathrm{p}<0.001)$. In Cur $+\mathrm{NZnO}$ treated animals, serum activity of ALT, AST and ALP were $47 \%, 41 \%$ and $30 \%$, respectively, lower than the NZnO-intoxicated rats $(p<0.05)$. These results are shown in Table 1.

\section{MDA level, SOD and GPx activities}

In the Cur group, MDA levels and SOD and GPx activities were not significantly altered. In NZnO-intoxicated rats, the hepatic level of MDA was significantly elevated by more than 2-fold in comparison to the control animals. In Cur+NZnO treated rats, MDA level was 39\% lower than in the NZnOintoxicated group $(\mathrm{p}<0.01)$. In the $\mathrm{NZnO}$-intoxicated group, hepatic GPx and SOD activities were decreased by 1.5- and 3.5 -fold, respectively $(\mathrm{p}<0.001)$. In Cur $+\mathrm{NZnO}$ treated rats, 
SOD and GPx activities were (156\%) and (26\%), respectively, higher than the NZnO-intoxicated rats $(\mathrm{p}<0.05)$. These data are shown in Table 2.

\section{Histological analysis}

Normal liver architecture was observed in control and Cur groups (Figure 2a, b). Lobular structures of the liver were damaged in NZnO-intoxicated rats. Centrilobular hepatocytes showed microvesicular steatosis (accumulation of small lipid droplets in cytoplasm). Accumulation of erythrocytes in central vein and sinusoids and infiltration of inflammatory cells were also observed in this group (Figure 2c).

TABLE 1. Biochemical tests of control and experimental groups. Values expressed as mean $\pm \mathrm{SD}$

\begin{tabular}{lccc}
\hline Groups & ALT (U/L) (n: 8) & AST (U/L) (n: 8) & ALP (U/L) (n: 8) \\
\hline Control & $90 \pm 9$ & $130 \pm 29$ & $400 \pm 55$ \\
Cur & $88.6 \pm 11$ & $127 \pm 30$ & $380 \pm 42$ \\
NZnO & $245 \pm 19^{* * *}$ & $365 \pm 19^{* * *}$ & $789 \pm 59^{* * *}$ \\
NZnO+Cur & $128 \pm 12^{* \dagger \dagger}$ & $214 \pm 2^{0^{*} \dagger}$ & $550 \pm 38^{* * \dagger}$ \\
\hline
\end{tabular}

SD: standard deviation; ALT: alanine aminotransferase; AST: aspartate aminotransferase; ALP: alkaline phosphatase

${ }^{*} \mathrm{p}<0.05,{ }^{* *} \mathrm{p}<0.01$ and ${ }^{* * *} \mathrm{p}<0.001$ vs. control, ${ }^{\dagger} \mathrm{p}<0.01,{ }^{\dagger} \mathrm{p}<0.001$ vs. NZnO-intoxicated groups

TABLE 2. MDA level, SOD and GPx activities of control and experimental groups. Values expressed as mean $\pm \mathrm{SD}$

\begin{tabular}{lccc}
\hline & $\begin{array}{c}\text { Lipid peroxidation nmol } \\
\text { MDA eq/g tissue } \\
\text { Groups }\end{array}$ & $\begin{array}{c}\text { SOD (U/mg protein) } \\
\text { (n: } 8)\end{array}$ & $\begin{array}{c}\text { GPx (U/mg protein) } \\
\text { (n: } 8)\end{array}$ \\
\hline Control & $0.21 \pm 0.05$ & $1.97 \pm 0.12$ & $176 \pm 20$ \\
Cur & $0.19 \pm 0.03$ & $2.22 \pm 0.24$ & $194 \pm 15$ \\
NZnO & $0.49 \pm 0.06^{* * *}$ & $0.51 \pm 0.27^{* * *}$ & $117 \pm 13^{* * *}$ \\
NZnO+Cur & $0.30 \pm 0.04^{* * \dagger}$ & $1.31 \pm 0.09^{* *+\dagger}$ & $147 \pm 19^{* \dagger}$
\end{tabular}

SD: standard deviation; MDA: malondialdehyde; SOD: superoxide dismutase, GPx: glutathione peroxidase

${ }^{*} \mathrm{p}<0.05,{ }^{* * *} \mathrm{p}<0.01$ and ${ }^{* * * *} \mathrm{p}<0.001$ vs. control, ${ }^{\dagger} \mathrm{p}<0.01,{ }^{\dagger \dagger} \mathrm{p}<0.001$ vs. NZnO-intoxicated groups
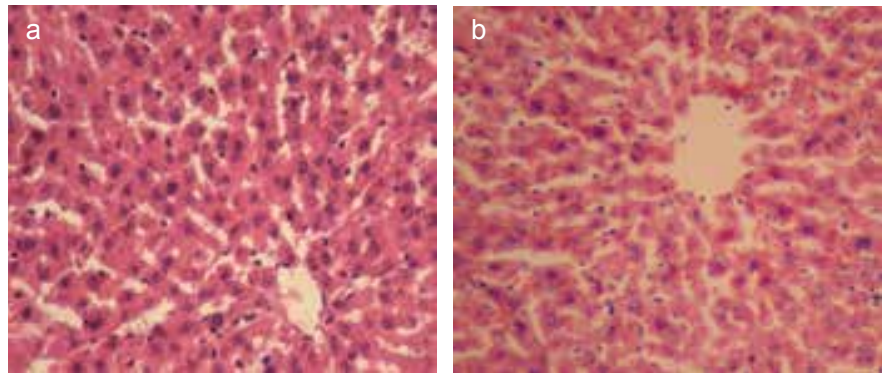

These histological changes were effectively reversed by Cur (Figure 2d).

\section{TUNEL assay}

In the Cur-treated group, the percentage of apoptosis was not significantly altered. In the $\mathrm{NZnO}$-intoxicated rats, the apoptosis index was significantly higher than in the control group $(\mathrm{p}<0.001)$. In Cur $+\mathrm{NZnO}$ treated animals, the apoptosis index was significantly reduced when compared to $\mathrm{NZnO}$-intoxicated animals $(p<0.05)$. These results are shown in Figures 3 and 4.

\section{DISCUSSION}

In the present study, we have demonstrated that the oral administration of Cur has hepatoprotective effects against $\mathrm{NZnO}$ in rats. $\mathrm{NZnO}$ significantly increased the serum activity of ALT, AST and ALP. The elevated ALT, AST and ALP activity was attenuated $(47 \%, 41 \%$ and $30 \%$, respectively) by Cur treatment.

The serum activity of these enzymes is routinely measured for the detection of liver disorders (19). The liver cells release these enzymes into the blood stream following injury or death. Reversal of the elevation of plasma enzyme activity in NZnOinduced hepatotoxicity indicates that Cur may decrease liver cell death.

The elevated MDA levels and the decreased SOD and GPX activity in liver tissue suggests the enhanced formation of lipid peroxidation leading to hepatotoxicity and a deficiency of antioxidant protection against the formation of excessive free radicals. Sharma et al. (11) have demonstrated that oxidative stress mediates cytotoxicity induced by $\mathrm{NZnO}$ in human liver cells. Sha et al. (20) have revealed that oxidative stress has an important role in the hepatotoxicity induced by NPs.

The increased MDA level in NZnO-intoxicated animals was attenuated $(39 \%)$ by Cur treatment. Cur could also increase the SOD and GPx activity (156\% and 26\%, respectively) in
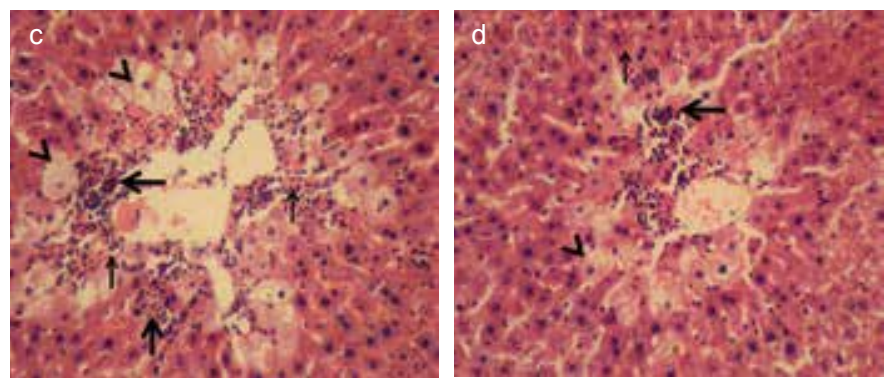

FIG. 2. a-d. Light microscopy of cross-sections of H\&E stained liver from the control and experimental groups. In the control group (a) and Cur group (b), normal architecture of the liver is observed (×250). In the NZnO group (c), the infiltration of leukocytes (thick arrow), congestion of erythrocytes (thin arrow) and microvesicular steatosis (arrowhead) are seen ( $\times 400)$. (d) NZnO-induced histologic changes are reduced by Cur treatment $(\times 400)$. 

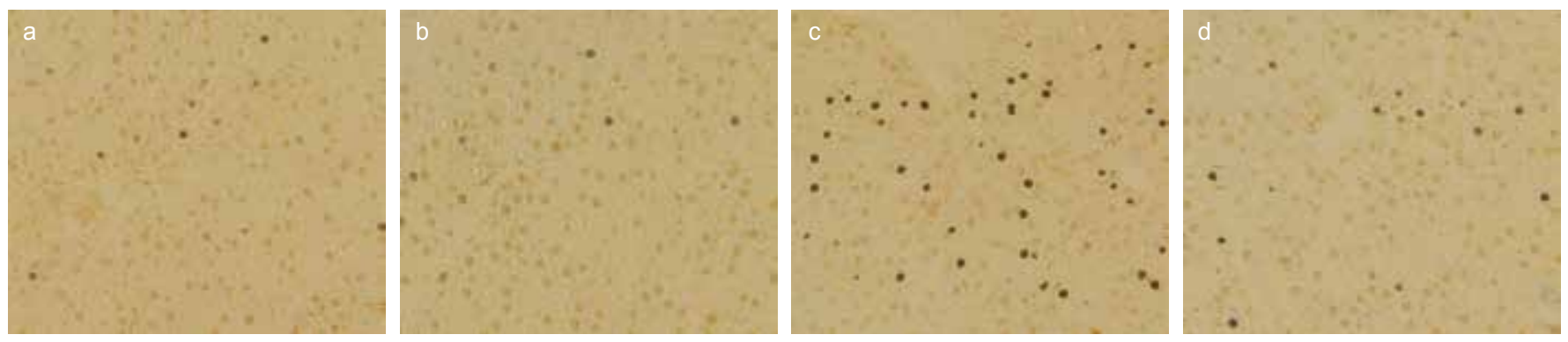

FIG. 3. a-d. Light microscopy of cross-sections of TUNEL stained liver from the control and experimental groups ( $\times 250)$. In the control (a) and Cur (b) groups, a few TUNEL-positive cells are seen. In the NZnO group (c), a clear increase in the number of TUNEL-positive hepatocytes are observed. (d) Treatment of Cur considerably reduced the number of TUNEL-positive cells. Arrows indicate TUNEL-positive cells.

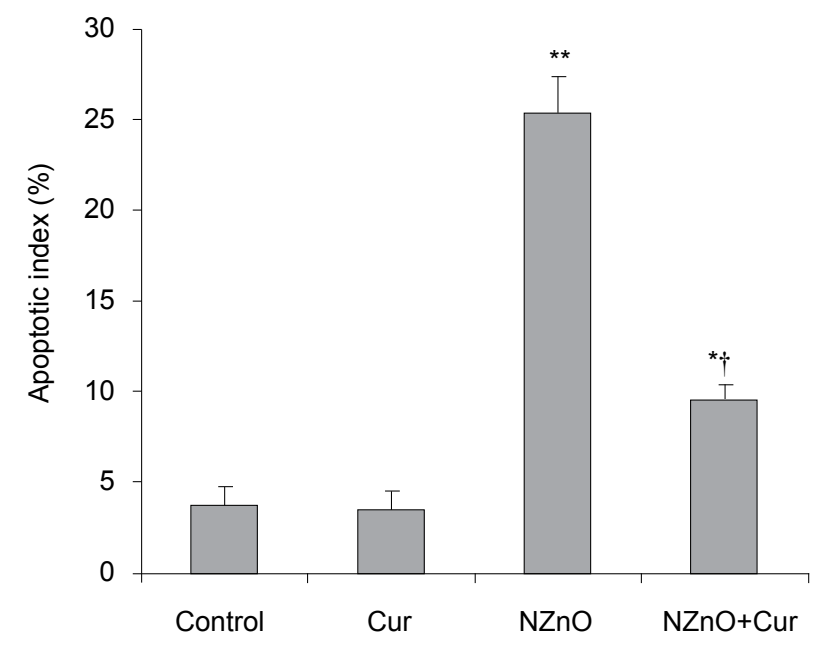

FIG. 4. Apoptotic index of control and experimental groups. Values are expressed as mean $\pm S D$ for 8 mice. ${ }^{*} p<0.01$ and ${ }^{* *} p<0.001$ vs. control, ${ }^{\dagger} \mathrm{p}<0.001$ vs. NZnO-intoxicated groups

NZnO-intoxicated animals. Hence, the hepatoprotective effect of Cur may be due to its antioxidant action.

The histological observations revealed necrosis and microvesicular steatosis (fatty change) in NZnO-treated rats. The accumulation of erythrocytes in central vein and sinusoids and the infiltration of inflammatory cells indicate that $\mathrm{NZnO}$ induces necrosis in liver tissue. It is known that acute or chronic fatty changes induced by a variety of drugs and chemicals substances relate to the formation of lipid peroxidation in mice. The exact mechanism of the formation of microvesicular steatosis has not been identified, but it appears that oxidative stress-induced mitochondrial damage plays a key role (21).

Apoptosis was also induced by $\mathrm{NZnO}$ in hepatocytes. Sha et al. (20) reported that apoptosis and necrosis occurs in BRL-3A cells treated with $\mathrm{NZnO}$ (17). Leist et al. (22) stated that "both apoptosis and necrosis can occur at the same time in the same tissue" (23). Recent studies show a close interplay between different types of cell death. Several common agents mediate apoptosis and necrosis events. Oxidative stress can induce cell death by various signaling pathways. It is revealed that severe oxidative stress is related to necrosis, while lesser degrees of oxidative stress induce apoptosis (24). NZnO may be accumulated to different levels in hepatocytes. It is possible that the accumulation of large amounts $\mathrm{NZnO}$ in hepatocytes induces necrosis while the accumulation of $\mathrm{NZnO}$ in lesser amounts results in apoptosis in these cells.

Cur improves the structure of the liver, and reduces microvesicular steatosis, congestion of erythrocytes and the infiltration of inflammatory cells. In addition, Cur could effectively reduce the percentage of apoptosis in hepatocytes. Many studies have shown anti-apoptotic effects of Cur; Jones et al. (25) revealed that treatment with Cur can inhibit apoptosis.

The bioavailability of Cur was not measured in present study, but it is well known that Cur has poor bioavailability (25). However, Cur has therapeutic effects against some types of cancer, diabetes, arthritis, neurological disorders, etc. (26).

No protective mechanisms of Cur were revealed in this experimental study. The antioxidative property of Cur may play a key role. Oxidative stress can stimulate various types of cell death. Thus, Cur may suppress NZnO-induced cell death by reducing oxidative stress. Wan et al. (27) demonstrated that Cur can effectively reduce oxidative stress and apoptosis in copper-induced hepatotoxicity.

In summary, we demonstrated that Cur can effectively protect against NZnO-induced cell death in rat liver tissue. Further investigations are required to explore crosstalk between apoptosis and necrosis mediated by Cur and $\mathrm{NZnO}$ in liver tissue.

Ethics Committee Approval: Ethics committee approval was received for this study from the Local Ethics Committee (approve number: CMRC-108).

\section{Informed Consent: N/A.}

Peer-review: Externally peer-reviewed.

Author contributions: Concept - Z.J., E.M.; Design - Z.J., E.M.; Supervision - L.K.; Resource - M.O., L.K.; Materials; Data Collec- 
tion and/or Processing - Z.J.; Analysis and/or Interpretation - L.K.; Literature Search- E.M, Z.J., L.K.; Writing - L.K.; Critical Reviews - L.K., M.O.

Acknowledgements: This paper is part of M. Sc thesis for Zahra Jozi and was supported by a Grant (CMRC-108) from the research council of the Ahvaz Jundishapur University of Medical Sciences.

Conflict of Interest: No conflict of interest was declared by the authors.

Financial Disclosure: The authors declared that this study has received no financial support.

\section{REFERENCES}

1. Borm PJA, Kreyling W. Toxicological hazards of inhaled nanoparticles-potential implications for drug delivery. J Nanosci Nanotechnol 2004;4:521-31. [CrossRef]

2. Lasagna-Reeves C, Gonzalez-Romero D, Barria MA, Olmedo I, Clos A, Sadagopa Ramanujam VM, et al. Bioaccumulation and toxicity of gold nanoparticles after repeated administration in mice. Biochem Biophys Res Commun 2010;393:649-55. [CrossRef]

3. Burnett ME, Wang SQ. Current sunscreen controversies: a critical review. Photodermatol Photoimmunol Photomed 2011;27:58-67. [CrossRef]

4. Bai XD, Gao PX, Wang ZL, Wang EG. Dual-mode mechanical resonance of individual $\mathrm{ZnO}$ nanobelts. Appl Phys Lett 2003;82:4806-8. [CrossRef]

5. Kairyte K, Kadys A, Luksiene Z. Antibacterial and antifungal activity of photoactivated $\mathrm{ZnO}$ nanoparticles in suspension. $J$ Photochem Photobiol B 2013;128:78-84. [CrossRef]

6. Filipe P, Silva JN, Silva R, Cirne de Castro JL, Marques Gomes $\mathrm{M}$, Alves LC, et al. Stratum corneum is an effective barrier to $\mathrm{TiO}_{2}$ and $\mathrm{ZnO}$ nanoparticle percutaneous absorption. Skin Pharmacol Physiol 2010;22:266-75. [CrossRef]

7. Emamifar A, Kadivar M, Shahedi M, Soleimanian-Zad S. Effect of nanocomposite packaging containing $\mathrm{Ag}$ and $\mathrm{ZnO}$ on inactivation of Lactobacillus plantarum in orange juice. Food Control 2011;22:408-13. [CrossRef]

8. Böckmann J, Lahl H, Eckert T, Unterhalt B. Titanium blood levels of dialysis patients compared to healthy volunteers. Pharmazie 2000;55:468-76.

9. Ben-Slama I, Amara S, Mrad I, Rihane N, Omri K, Ghoul J, et al. Sub-Acute Oral Toxicity of Zinc Oxide Nanoparticles in Male Rats. J Nanomed Nanotechnol 2015;6:284.

10. Guan R, Kang T, Lu F, Zhang Z, Shen H, Liu M. Cytotoxicity, oxidative stress, and genotoxicity in human hepatocyte and embryonic kidneycells exposed to $\mathrm{ZnO}$ nanoparticles. Nanoscale Res Lett 2012;7:602. [CrossRef]

11. Sharma V, Anderson D, Dhawan A. Zinc oxide nanoparticles induce oxidative stress and genotoxicity in human liver cells (HepG2). J Biomed Nanotechnol 2011;7:98-9. [CrossRef]
12. Chattopadhyay I, Biswas K, Bandyopadhyay U, Banerjee RK. Turmeric and curcumin: Biological actions and medicinal applications. Cur Sci 2004;87:44-53.

13. Farombi EO, Shrotriya S, Na HK, Kim SH, Surh YJ. Curcumin attenuates dimethylnitrosamine-induced liver injury in rats through Nrf2-mediated induction of heme oxygenase-1. Food Chem Toxicol 2008;46:1279-87. [CrossRef]

14. García-Niño WR, Pedraza-Chaverrí J. Protective effect of curcumin against heavy metals-induced liver damage. Food Chem Toxicol 2014;69:182-201. [CrossRef]

15. Nabavi SF, Daglia M, Moghaddam AH, Habtemariam S, Nabavi SM. Curcumin and liver disease: from chemistry to medicine. Comprehensive Reviews in Food Science and Food Safety 2014; 13:62-77. [CrossRef]

16. Sehgal A, Kumar M, Jain M, Dhawan D. Combined effects of curcumin and piperine in ameliorating benzo (a) pyrene induced DNA damage. Food Chem Toxicol 2011;49:3002-6. [CrossRef]

17. Wells MA, Abid A, Kennedy IM, Barakat AI. Serum proteins prevent aggregation of $\mathrm{Fe}_{2} \mathrm{O}_{3}$ and $\mathrm{ZnO}$ nanoparticles. Nanotoxicology 2012;6:837-46. [CrossRef]

18. Orazizadeh M, Fakhredini F, Mansouri E, Khorsandi L. Effect of glycyrrhizic acid on titanium dioxide nanoparticles-induced hepatotoxicity in rats. Chem Biol Interact 2014;220:214-21. [CrossRef]

19. Aragon G, Younossi ZM. When and how to evaluate mildly elevated liver enzymes in apparently healthy patients. Cleve Clin $J$ Med 2010;77:195-204. [CrossRef]

20. Sha B, Gao W, Wang S, Gou X, Li W, Liang X, et al. Oxidative stress increased hepatotoxicity induced by nano-titanium dioxide in BRL-3A cells and Sprague-Dawley rats. J Appl Toxicol 2014;34:345-56. [CrossRef]

21. Letteron P, Fromenty B, Terris B, Degott C, Pessayre D. Acute and chronic hepatic steatosis lead to in vivo lipid peroxidation in mice. J Hepatol 1996;24:200-8. [CrossRef]

22. Leist M, Single B, Castoldi AF, Kuhnle S, Nicotera P. Intracellular adenosine triphosphate (ATP) concentration: a switch in the decision between apoptosis and necrosis. $J$ Exp Med 1997;185:1481-6. [CrossRef]

23. Elmore S. Apoptosis: A Review of Programmed Cell Death. Toxicol Pathol 2007;35:495-516. [CrossRef]

24. Nikoletopoulou V, Markaki M, Palikaras K, Tavernarakis N. Crosstalk between apoptosis, necrosis and autophagy. Biochim Biophys Acta 2013; 1833:3448-59. [CrossRef]

25. Jones EA, Shahed A, Shoskes DA. Modulation of apoptotic and inflammatory genes by bioflavonoids and angiotensin II inhibition in ureteral obstruction. Urology 2000;56:346-51. [CrossRef]

26. Anand P, Kunnumakkara AB, Newman RA, Aggarwal BB. Bioavailability of curcumin: problems and promises. Mol Pharm 2007;4:807-18. [CrossRef]

27. Wan XH, Li YW, Luo, XP. Curcumin attenuated the lipid peroxidation and apoptotic liver injury in copper-overloaded rats. Zhonghua Er Ke Za Zhi 2007;45:604-8. 